\title{
«Erfolgsmuster: Kundennutzen durch digitale Transformation?» \\ - Einleitung \\ zu den Fallstudien
}

Elke Brucker-Kley 
Welche Erfahrungen, Lösungsansätze und Resultate weisen Unternehmen auf, die den Kundennutzen und die Möglichkeiten der Digitalisierung ins Zentrum ihrer Prozessmanagement-Initiativen stellen? Welche Methoden und Werkzeuge setzen sie ein? Wie wirken sich diese Aktivitäten auf das Geschäftsmodell, die Business Operations und das Kundenerlebnis aus? Diese Fragen waren Gegenstand der Interviews mit den Firmenvertretern und standen im Mittelpunkt des Praxisworkshops, die im Rahmen des qualitativen Forschungsteils der Studie im Juni 2016 durchgeführt wurden.

Ziel des Praxisworkshops war es, Unternehmen unterschiedlicher Branchen zusammenzubringen, die Prozessmanagement auf einem ähnlich hohen Niveau betreiben, um ihre Fallbeispiele im Expertenkreis zu diskutieren. Durchgeführt und moderiert wurde der Workshop vom Institut für Wirtschaftsinformatik und dem Institut für Marketingmanagement der ZHAW School of Management and Law. Für die Vorbereitung, Diskussion und Analyse der Fallstudien kam das in Abschn. 1.3 vorgestellte thematische Rahmenwerk zur Anwendung.

Die Fallstudien und deren Analyse sind Gegenstand der nachfolgenden Kapitel. Erkenntnisse aus den Fallstudien und den Diskussionen im Workshop werden im Fazit im Sinne von Erfolgsmustern zusammengefasst (Abschn. 9.2)

Das Studienteam dankt allen am Workshop beteiligten Unternehmen (- Abb. 3.1), die ihr Expertenwissen und ihre wertvolle Zeit für die Vorbereitung, Diskussion und Auswertung der Fallstudien bereitgestellt haben.

\begin{tabular}{|c|c|c|}
\hline Fallstudie & Thema & Präsentiert von \\
\hline amag Leasing & $\begin{array}{l}\text { Videobasierte Identifikation als Wegbereiter für das } \\
\text { Online-Leasing }\end{array}$ & $\begin{array}{l}\text { Esad Ceranic } \\
\text { Projektverantwortlicher Business } \\
\text { Analyst } \\
\text { Patrick Frauchiger } \\
\text { Leiter Marketing und Verkauf }\end{array}$ \\
\hline Kanton Zürich & eUmzug - elektronisch umziehen einfach gemacht & $\begin{array}{l}\text { Lukas Steudler } \\
\text { Leiter Geschäftsstelle egovpartner.zh.ch } \\
\text { Staatskanzlei des Kantons Zürich }\end{array}$ \\
\hline iII Swiss $\mathrm{Re}$ & $\begin{array}{l}\text { Case Management in P\&C Reinsurance: } \\
\text { Wissensarbeit im Fokus }\end{array}$ & $\begin{array}{l}\text { Marco Peyer } \\
\text { Head BPM \& Service Operations } \\
\text { P\&C Re-Insurance }\end{array}$ \\
\hline 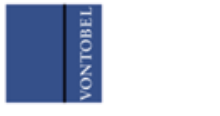 & Service Management schafft Kundennutzen & $\begin{array}{l}\text { Markus Schneider } \\
\text { Head Operational Services } \\
\text { Philipp Klauser, } \\
\text { Applikationsverantwortlicher Jira }\end{array}$ \\
\hline$\bigodot_{\text {swisscom }}$ & $\begin{array}{l}\text { Einführung von Produkt- \& Servicekatalogen: Der } \\
\text { erste Schritt zur industrialisierten Fertigung }\end{array}$ & $\begin{array}{l}\text { Andreas Hilber } \\
\text { Head of Process Architecture Network } \\
\text { and IT Operations }\end{array}$ \\
\hline
\end{tabular}

- Abb. 3.1 Die Fallstudien im Überblick

Open Access Dieses Kapitel wird unter der Creative Commons Namensnennung 4.0 International Lizenz (http://creativecommons.org/licenses/by/4.0/deed.de) veröffentlicht, welche die Nutzung, Vervielfältigung, Bearbeitung, Verbreitung und Wiedergabe in jeglichem Medium und Format erlaubt, sofern Sie den/die ursprünglichen Autor(en) und die Quelle ordnungsgemäß nennen, einen Link zur Creative Commons Lizenz beifügen und angeben, ob Änderungen vorgenommen wurden. 
Die in diesem Kapitel enthaltenen Bilder und sonstiges Drittmaterial unterliegen ebenfalls der genannten Creative Commons Lizenz, sofern sich aus der Abbildungslegende nichts anderes ergibt. Sofern das betreffende Material nicht unter der genannten Creative Commons Lizenz steht und die betreffende Handlung nicht nach gesetzlichen Vorschriften erlaubt ist, ist für die oben aufgeführten Weiterverwendungen des Materials die Einwilligung des jeweiligen Rechteinhabers einzuholen.

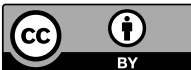

